\title{
Um Estudo Sobre o Conceito de Natureza
}

\section{A study on the Concept of Nature}

\author{
Daniel Stella Castro* $\square$ (iD \\ Pós-doutorando no Departamento de Economia, Sociologia e Tecnologia. \\ Faculdade de Ciências Agronômicas, Universidade Estadual Paulista \\ "Júlio de Mesquita Filho" - Botucatu, Brasil. \\ *E-mail para correspondência: daniel.scastro@gmail.com (DSC).
}

Recebido (Received): 20/03/2019 Aceito (Accepted): 28/06/2019.

\begin{abstract}
Resumo: A partir da revisão bibliográfica de "A História da ideia de Natureza" de Robert Lenoble, "A Natureza", de Maurice Merleau-Ponty e "The Concept of Nature" de Alfred Whitehead, o principal objetivo do presente estudo foi apresentar de maneira sintética as principais noções e conceitos de Natureza discutidos em tais obra, como: Natureza mágica; Natureza como finalidade; Natureza como exterioridade; Natureza como um sistema; Natureza humanista e; o natural na Natureza. Assim, se buscou demonstrar a dificuldade em traçar limites para uma definição única e objetiva sobre Natureza. Posto isso, concluiu-se que a Natureza isolada em diferentes aspectos é uma abstração científica eleita como método em diversos campos disciplinares na busca de entender um determinado fenômeno. Nesse sentido, postula-se que a maneira como um indivíduo ou um grupo social entende a Natureza tem relação direta com suas atitudes no mundo vivido, atitudes que são construídas culturalmente.
\end{abstract}

Palavras Chaves: Natureza; Cultura, Conceitos.

Abstract: From the bibliographical review of Robert Lenoble's "The History of the idea of Nature", Maurice Merleau-Ponty's "Nature" and Alfred Whitehead's "The Concept of Nature", the objective of this paper was to present in a synthetic way the main notions and concepts of Nature discussed in such works, as: Magical Nature; Nature as purpose; Nature as exteriority; Nature as a system; Humanistic Nature and; the natural in Nature. Then, this paper aims to appoint the dificulty in Nature's deffinition. Also, the scientific abstraction of partition Nature in different aspects is a method chosen in several disciplinary fields in order to understand a certain phenomenon. In this sense, the attitudes which an individual or a social group have in the environment are directly related to their understandment of Nature and such attitudes are culturally constructed.

Keyword: Nature, Culture, Concepts.

\section{Introdução}

"Como todas as palavras que designam uma ideia muito geral, a palavra Natureza parece clara quando a empregamos, mas quando sobre ela reflectimos, parece-nos complexa e talvez mesmo obscura" (LENOBLE, 2002 [1968], p 183).

"Para a maior parte de nós, a [Natureza] é apenas um ser vago e distante, sufocado pelas cidades, pelas ruas, pelas casas, e, sobretudo pela presença dos outros homens" (MERLEAU-PONTY, 2011 [1945], p 49).

O esforço da discussão apresentada no presente trabalho é mostrar que a Natureza não se reduz à ideia que se tem ou se faz sobre um ambiente pouco modificado pelo homem e geralmente localizado em áreas distantes dos grandes centros urbanos, ou ambientes distantes do contato com as ações humanas, e muito menos algo restrito à qualidade natural dos objetos e dos seres.

Posto isso, foi colocado como principal esforço no presente trabalho traçar alguns apontamentos teóricos para indicar que apesar da Natureza ser aquilo que está dado no mundo vivido, este termo é apropriado e 
utilizado no cotidiano conforme a representação que é feita dele, segundo noções e conceitos herdados ou construídos culturalmente.

Assim, a partir da leitura e revisão da obra " A História da ideia de Natureza" se chegou a duas outras obras que dialogam entre elas. Tais obras são: "A Natureza" e; "The Concept of Nature".

O termo Natureza é originário da derivação do verbo grego $\varphi v ́ \omega$ (foneticamente /fío/), no sentido de fazer nascer e crescer, engendrar, em alusão ao vegetal. Essa concepção relaciona-se à ideia de espontaneidade criativa, de nascimento, de desenvolvimento harmonioso (EHRARD, 1994 [1963]; MERLEAU-PONTY 2006 [1995]). Em latim, o termo Natureza tem relação com a palavra nascor - que se refere a nascer, viver e provavelmente seu significado fixou-se a partir do sentido nascer. Portanto, no sentido primordial do termo Natureza, tendo como referência a língua grega e latina, Merleau-Ponty (2006 [1995], p. 4) refere-se à Natureza como o que está "por toda parte onde há uma vida que tem um sentido mas onde, porém, não existe pensamento; daí o parentesco com o vegetal [e acrescenta expandindo tal definição dizendo]: é Natureza o que tem um sentido, sem que esse sentido tenha sido estabelecido pelo pensamento."

Eagleton (2003, p. 15) fornece a mesma noção sobre Natureza pelo caminho contrário, ou seja, buscando discutir a ideia de cultura, por exemplo, quando afirma que "[como] cultura, a palavra natureza significa tanto o que está a nossa volta como o que está dentro de nós [...]."

As duas sínteses citadas acima sobre Natureza, de certa maneira já sinalizam os limites culturalmente utilizados atualmente pelos diversos grupos sociais humanos colocados entre as ideias de Natureza mágica de um lado, e do outro uma Natureza racionalizada. Contudo, na definição desses limites não foi considerado como marco uma discussão acerca da gênese da ideia de Natureza.

Sendo assim, a estrutura definida para apresentação das noções e conceitos de Natureza no presente artigo apoiou-se em três obras, são elas: "A História da ideia de Natureza" de Lenoble (2002 [1968]); "A Natureza”, de Merleau-Ponty (2006 [1995]); "The Concept of Nature”, de Whitehead (1930).

\section{Objetivo}

A partir das obras "A História da ideia de Natureza", "A Natureza" e "The Concept of Nature" apresentar de maneira sintética as principais noções e conceitos de Natureza com intuito de lançar ao debate acadêmico interdisciplinar a dificuldade em traçar limites para uma definição única e objetiva sobre Natureza.

\section{Metodologia}

Primeiramente as três obras dos autores supracitados foram revisadas no sentido de compilar e sintetizar as principais ideias e noções tratadas por eles acerca do termo Natureza. Entretanto, para dar conta de tal tarefa, durante o processo de revisão foi necessário acessar obras de outros autores que de certa maneira deram suporte direto ou indireto à construção das ideias apresentadas nas três principais obras tratadas no presente trabalho. Neste sentido, ao menos duas leituras foram realizadas em cada uma das três principais obras revisadas para chegar a um formato de síntese e apresentação da principais noções e ideias acerca de Natureza, apresentados no item 4 do presente trabalho. Assim, somente com o objetivo didático de apresentação do resultado de tal esforço, as principais ideias e noções acerca de Natureza foram agrupadas em seis itens. São eles: A ideia de Natureza Mágica; A ideia finalista de Natureza; A Natureza como exterioridade; A Natureza como máquina; A ideia humanista de Natureza, e; O natural percebido.

Tal formato nasceu da reflexão sobre as afirmações, definições, noções e ideias apresentadas nas três obras supracitadas de Lenoble, Merleau-Ponty e Whitehead e, sobretudo, da avaliação do autor no presente artigo ao notar que as obras dialogam entre si. Suscintamente, tal exercício com intuito de compilar as diferentes ideias e noções é apresentado nos seis primeiros parágrafos do item Resultados e Discussão.

Basicamente, a primeira obra revisada foi a História da ideia de Natureza. Para o entendimento e interpretação da discussão apresentada nela foi imprescindível uma introdução à discussão acerca da percepção. Nesse sentido chegou-se a Merleau-Ponty por meio da obra "Fenomelogia da Percepção". A partir dela chegou-se à obra "A Natureza" e nela verificou-se a importância que seria revisar a obra de Whitehead. Vale ressaltar que Santos (2002) também cita Whitehead em a "Natureza do Espaço". 


\section{Resultados e Discussão}

À parte da Natureza mágica como acepção inicial da ideia de Natureza, Merleau-Ponty (2006 [1995]) explana sobre o sentido finalista em Aristóteles e nos estoicos. O sentido finalista se relaciona à ideia de uma orientação para um tipo, uma ordem, um destino para explicar os fenômenos sob um ponto de vista qualitativo da Natureza total.

Nos três campos gerais propostos por Lenoble (2002 [1968]) acerca da noção de Natureza - científico; moral; estético - o animismo, que seria uma das características principais na Natureza mágica, mostra uma relação com a moralidade. Uma moral fundamentada no medo de não encontrar correlativos a partir de sua percepção no exterior ao seu corpo, portanto imaginando uma Natureza. Nesse sentido, uma moral fundamentada também na culpa e no amor (EHRARD, 1994 [1963]).

Outra ideia importante de Natureza é a de objeto puro, ou seja, que ela é um ser exterior ao homem e exterior a si mesmo, feita de partes exteriores (MERLEAU-PONTY, 2006 [1995]). A origem dessa ideia é muito antiga, remonta aos períodos dos filósofos gregos clássicos, podendo ser encontrada em Epicuro e Lucrécio.

Já na concepção pagã de Natureza (nesse caso, pagã tendo como referência uma concepção de ideologia religiosa em outras divindades, portanto pagã em relação ao cristianismo que também constitui uma concepção filosófica sobre Natureza) a necessidade natural exclui a ideia de providência divina, e a bondade da Natureza ignora o pecado. Mas essa ideia de Natureza bondosa é imposta aos seus fiéis também pelo medo da desobediência das regras existentes em tais religiões. De qualquer forma, desde os primeiros séculos da era cristã, há embates entre os preceitos cristãos e pagãos acerca da ideia de Natureza. Entre os séculos XVI e XVIII, na Europa ocidental, há um recrudescimento dos embates (EHRARD, 1994 [1963]).

A ideia de Alma mater, preponderante no período Renascentista, seria uma miscigenação da Natureza mágica (ideia pagã) com a Natureza objeto, sedimentadas nos preceitos da tradição judaico-cristã. Nessa linha desdobrar-se-iam as noções de naturante e naturado, sobretudo, no entendimento de uma Natureza divina e a natureza de um Eu pensante. A ideia de uma Natureza pura, livre de pecados, e uma Natureza terrena, perigosa, amedrontadora, influenciaram nessa dicotomia.

[...], foi uma concepção qualitativa do Mundo que impediu Kepler de admitir a lei da gravitação universal. Faltou-lhe substituir a Natureza dividida em regiões qualitativamente distintas por uma Natureza em que o Ser é homogêneo em toda a parte e sempre [...].

Tampouco é para refutar a idéia de finalidade que Descartes e Newton formulam a nova idéia de Natureza. Neles a finalidade não é rejeitada mas sublimada em Deus. $\mathrm{O}$ elemento novo reside na idéia de infinito devido à tradição judaico-cristã. A partir desse momento, a Natureza desdobra-se em um naturante e naturado. É então em Deus que se refugia tudo o que podia ser interior à Natureza. O sentido refugiase no naturante; o naturado torna-se produto, pura exterioridade.

Não obstante, a partir do momento em que se pensa a idéia de criação infinita, a cisão torna-se não obrigatória, mas tentadora. A oposição naturansnaturata data do século XII [...], mas a idéia judaico-cristã não tinha por função estabelecer essa cisão. Na Natura naturata, a palavra Natureza é conservada; isso permite a Santo Tomás anexar a idéia grega de Natureza, [ou seja,] "o estado de natureza" antes do pecado, e outra para depois do pecado, em que o Bem e a Natureza não podem ser postos juntos (MERLEAU-PONTY, 2006 [1995], p 10).

Segundo Ehrard (1994 [1963]), em 1694 o dicionário da Academia Francesa distingue sete sentidos para a palavra Natureza, são eles: (i) o conjunto do universo e de todas as coisas criadas; (ii) o espírito universal difundido em cada coisa criada, pelos quais essas coisas têm seu início, meio e fim; (iii) o princípio interno de cada Ser; (iv) o movimento pelo qual cada homem tem em relação às coisas que podem contribuir para sua conservação; (v) a aparência, o temperamento; (vi) certa disposição da alma; (vii) o estado natural do homem por oposição ao da graça.

Ehrard afirma que os sentidos (iii), (iv), (v) e (vi) são especificações do último, e pensando sobre o ambiente dessa época, sobretudo à luz da ideologia religiosa que compunha a conjuntura, o segundo sentido 
provavelmente era o mais utilizado, pois o primeiro e o último demonstravam incertezas acerca do papel do homem em relação a Deus, e a posição do homem em relação à Natureza.

Deve-se salientar que na evolução das ideias de Natureza, as posições fundamentais do pensamento filosófico encontram-se imbrincadas umas nas outras, quase sempre apresentado reminiscências da base de pensamento anterior na ulterior, ora como fonte de inspiração positiva, ora negativa, e até mesmo dialética. A nomenclatura utilizada nos próximos itens refere-se à característica mais forte dentro de cada noção de Natureza apresentada

\subsection{A ideia de Natureza mágica}

Essa ideia é envolta a uma maneira de viver, de ser, de consciência religiosa da Natureza através de sinais, deuses. Nesse sentido, os deuses expressavam suas vontades através da Natureza (LENOBLE, 2002 [1968]). "A Natureza de Homero [...] privada de intimidade, a alma não é mais que um lugar de passagem para as forças mágicas" (LENOBLE, 2002 [1968], p 55).

Na Natureza mágica, os acontecimentos considerados de ordem natural são expressões de um sentido divino aos comportamentos humanos. Com efeito, a vida e a consciência recebem sentido através de uma ideologia do natural (ou religião do natural) (LENOBLE, 2002 [1968], p 45). Na mentalidade mágica, os objetos carregam sinais que refletem a existência do divino. Os sonhos seriam uma interiorização dos aspectos existentes na exterioridade de seus corpos.

\subsection{A ideia finalista de Natureza}

O aparecimento de uma atitude desinteressada de observação ou análise da Natureza, marcando certo afastamento em tal processo, dá-se pelo desenvolvimento do sentimento estético acerca dela. Sócrates seria o símbolo dessa nova posição perante a Natureza. Ressalta-se que Sócrates se debruçava sobre o entendimento da natureza humana muito mais do que nas outras. Assim, ao pensar a república, a vida em sociedade, não buscava encontrar tal ordem na Natureza, tarefa na qual Platão se lançou (LENOBLE, 2002 [1968]).

Para Sócrates, a noção de Natureza esboça-se como:

[...] uma ordem, animada pela beleza, de retórica construtiva, de coragem, dominada pela Ideia de Bem. Ela é sol que ilumina tudo, pelo menos para a alma que soube libertar-se da sedução das sombras.

[...] Sócrates, se é que podemos aceitar o testemunho de Platão, não queria mal aos deuses mágicos das nascentes, das nuvens e dos bosques, só que já não tinha necessidade deles (LENOBLE, 2002 [1968], p 60).

Partindo da ordem e da hierarquização da cidade grega, Aristóteles projeta o mesmo padrão na Natureza, promovendo assim uma hierarquização dela. As coisas diante do homem são entendidas não mais como símbolos de pensamento mágico, mas sim "como seres dotados de uma alteridade radical" (LENOBLE, 2002 [1968], p 68). Nesse sentido, assume-se uma atitude em que além dos problemas dos homens, os problemas das coisas também passam a ter relevância nessa relação entre humanos e não humanos.

O pensamento mágico oscilava entre dois temas, em nada contraditórios mas ambivalentes: todo o ser é símbolo, todo o ser é uma alma. Para Aristóteles, o ser define-se pela sua <<natureza >>, e neste sentido <<a Natureza é um princípio $[\ldots]$ e uma causa [...] de movimento e, igualmente, de repouso para a coisa na qual reside imediatamente [...] e na qualidade de atributo essencial [...] e não acidental [...] dessa coisa. O ser natural é substância (LENOBLE, 2002 [1968], p 71).

$\mathrm{Na}$ Natureza Aristotélica, os homens projetavam suas percepções de senso comum nela. Assim, a partir de suas percepções, transportavam à Natureza as qualidades que os seus sentidos lhe apresentavam do fato observado. Cabe ressaltar que essa Natureza tinha estrutura e objetividade e não somente uma ordem humana.

O Aristotelismo influenciou os homens por vários séculos. Lenoble (2002 [1968], p 76) o sintetiza da seguinte maneira: 
1) Constituição de um campo racional entre a sobrevivência mágica das qualidades, no interior das coisas disponíveis para a nossa utilização, e a magia não encetada do mundo astral.

2) Mutação (herdada de Platão) do instinto místico, com o nascimento do tema do Eros, na Ideia de Bem, que coroa a ordem racional e resgata o pensamento do impasse mitológico.

3) Aparecimento dos $\langle<$ factos $\rangle>$, finalmente afastados do simbolismo mágico e início de uma ciência através da ligação coerente desses factos segundo o tipo de leis do pensamento artificialista.

Platão e Aristóteles projetavam numa Natureza idealizada ("Cosmos organizado e favorável ao homem") os seus desejos de uma sociedade melhor; "tinham-na colocado perante o Estado e o indivíduo como um modelo a imitar" (LENOBLE, 2002 [1968], p 102). Com efeito, uma crítica a esse pensamento, segundo Merleau-Ponty (2006 [1995]), é que o finalismo afirma um natural artificial, ou seja, uma espécie de artificialismo contemplativo fruto do aristotelismo.

Epicuro, apresentado no próximo item, teve uma postura completamente diferente de Platão e Aristóteles, pois assume uma posição desinteressada também em relação ao modelo humano. Assim, buscou um sistema de regras na Natureza com intuito de auxiliar e proteger a vida humana, mas não para oferecê-lo como modelo (LENOBLE, 2002 [1968]).

\subsection{A ideia de Natureza como Exterioridade - os Atomistas}

$\mathrm{Na}$ Antiguidade, destacam-se como representantes dessa corrente de pensamento Demócrito, Epicuro e Lucrécio (LENOBLE, 2002).

Os nossos temores, repete Epicuro, vêm todos da nossa propensão para propor de imediato uma explicação mítica dos dados sensíveis, onde alojamos todos os nossos sentimentos. O sábio não quer ver nada mais a não ser o que os seus olhos veem [...]. [A] Natureza tal como surge aos nossos sentidos, não apresenta nada de assustador; não basta também para elevar a nossa alma a um Deus que nos falaria por seu intermédio; todos estes sentimentos de esperança ou de temor vêm de nós; a Natureza é um jogo de fenómenos, engendrados pelo acaso, em que o sábio deve passar os anos da sua existência, mas sem procurar [...] uma solução para o problema da vida. Para ver tal como ela é, há, pois que observar com os nossos sentidos, sem preconceitos, sem sobrecarregar a nossa observação de preocupações morais ou religiosas que só a nós pertencem (LENOBLE, 2002. [1968], p 224).

Para Demócrito, não é a qualidade que existe, mas sim uma relação entre átomos e vazios que expressa a realidade. A qualidade seria uma Natureza aparente. (LENOBLE, 2002). Assim, considerando a Natureza como objeto puro, exterior ao homem e a ela mesma, "composta de partes extra partes", o homem não tem como investigar a Natureza em sua totalidade e "só o Todo existe verdadeiramente" (MERLEAU-PONTY, 2006 [1995], p 12).

Para Epicuro a ideia de espaço se dava pela posição relativa dos corpos uns aos outros. Aristóteles era contemporâneo de Epicuro e, enquanto junto a outros filósofos contemplava e estudava a Natureza para descobrir as regras que ela coloca aos homens, Epicuro a estudava para certificar-se de que não há regra nenhuma na Natureza (LENOBLE, 2002 [1968]).

A corrente de pensamento atomista também fora forjada para atender as próprias necessidades do homem, porém com a grande diferença da aceitação de como as coisas se apresentam no dia a dia. Em Epicuro há um movimento de desumanização da Natureza no sentido de sua materialização.

Um expoente seguidor dos estudos de Epicuro foi Lucrécio. Enquanto em Epicuro o estudo da Natureza ainda era feito por uma física da contemplação (sem pautar-se em leis ou ordem), Lucrécio desenvolve uma física de utilização, sob os preceitos de lei e ordem, no sentido de leis utilizáveis pelo homem na Natureza 
(LENOBLE, 2002 [1968]). Sua obra de grande influência nos filósofos e cientistas de diversas épocas é a Natura rerum.

Em outra corrente de pensamento que não se vale do atomismo e retomava noções do finalismo, pode-se dizer que Plínio foi um grande expoente. Plínio "contenta-se com o panteísmo sincrético, originário de reminiscências estoicas e platônicas, que satisfaz então a massa dos seus contemporâneos instruídos e permite um amplo recurso à finalidade que querem descobrir na Natureza providencial" símbolos para justificar a cultura religiosa (LENOBLE, 2002 [1968], p 120 e 121). Plínio afirma que o mundo é sagrado, representa o todo.

Em sua obra "História Natural", procura descrever a Natureza em uma espécie de catalogação. Essa obra teve imensa importância nos pensamentos e obras de vários filósofos e cientistas. Nela há uma grande influência das informações positivas de Aristóteles e Teofrasto.

Em Plínio há a evidência da relação das origens sociais e míticas do natural, as ideias de símbolos retornam para caracterizar a ideologia do natural, por exemplo, a árvore. Para Plínio a árvore ainda representava não uma coisa, mas uma espécie de dádiva, elas são consagradas aos deuses. Por fim, afirma que o homem está só perante a Natureza, que ela é a responsável por todos os males e diz que a Terra é a grande protetora do homem, a grande mãe.

Em resumo, a definição recebida dos Gregos, o natural é uma ordem independente das coisas humanas, aplicou-a Plínio, como tantos outros contribuintes helénicos, a uma afectividade muito mais primitiva. Demasiado próxima religiosamente dos antepassados venerados, de quem as velhas árvores das florestas foram contemporâneas, demasiado <<terrena〉>, demasiado caseira, a alma romana nunca se resignou a ver objectivamente a Natureza como um marinheiro que descobre uma terra estrangeira. A identificação da Roma política com o orbis terrarum terá ainda contribuído para esta ilusão (LENOBLE, 2002 [1968], p 159).

A Física qualitativa da [antiguidade] é o ordenamento das aparências em função do nosso modo de acção humano. [...] a Natureza é construída como um conjunto de qualidades exteriorizadas [...] (LENOBLE, 2002 [1968], p 160).

Lenoble (2002 [1968], p 233) aponta que apesar de todo o conhecimento da Antiguidade constantemente penetrar a Idade Média, houve certa regressão no desenvolvimento dos conhecimentos acerca dos estudos da Natureza. "[...] abandona-se a sistematização de Aristóteles para regressar a temas animistas, mágicos, muito velhos que remontam aos neoplatônicos [...] e até às tradições antigas do Egipto [...]." Há uma espécie de retorno à doutrina mestra da Alma do Mundo. A corrente dos escolásticos procura dentro dos dogmas cristãos restabelecer o equilíbrio entre o homem e a Natureza na Ciência.

Os pensadores do Renascimento, sobretudo a partir do século XVI, abandonaram sistematizações de estudos da Natureza, por exemplo, instituídas por Aristóteles e até da corrente dos escolásticos. Mas, a partir da contemplação da Natureza, influenciaram o grande avanço literário e artístico. Na ciência, segundo Lenoble (2002 [1968]), pouco se avançou em inovações relacionadas ao passado.

Termos como olho d'água ou o retorno do termo Mãe Natureza - Natura mater - remontam ao Renascimento, fruto de um movimento de restabelecimento do equilíbrio entre o Homem e Natureza pelos escolásticos, ao menos dentro da Ciência influenciada pelos dogmas católicos, cuja corrente predominante estava em crise, desdobrando-se na reforma protestante.

Esse naturalismo do Renascimento polariza de maneira contundente a vida espiritual dos homens. De qualquer forma, apesar das estruturas limitantes impostas pelo pensamento escolástico, no movimento Renascentista a Natureza foi sentida antes de ser pensada, e essa seria uma grande contribuição às alterações futuras das noções e concepções de Natureza (WHITEHEAD, 1930; LENOBLE, 2002 [1968]).

\subsection{A ideia de Natureza como Sistema de Princípios e de Leis ou Natureza Máquina}

Uma primeira fase desses princípios mecanicistas - libertação do homem dos temores da Natureza - podese afirmar que foi atingida na época de Platão e Aristóteles, conforme vimos anteriormente. 
Tal concepção sedimenta-se com o próprio movimento de prevalecimento do cristianismo, já que a vida cristã polariza o homem e Natureza. Nela a concepção de Natureza torna-se essencialmente jurídica e mecânica (LENOBLE, 2002 [1968]).

O finalismo em Descartes na ideia de Natureza, entretanto, é diferente dos filósofos gregos clássicos, pois para ele a finalidade tem sentido apenas ao homem. Há uma transformação dessa interpretação da ideia de finalidade na Natureza, visto que não há como prever as ações de Deus. A ideia de finalidade passa a não ter aplicabilidade, consequentemente a Natureza torna-se objeto, torna-se Natureza máquina. Nessa concepção ela é entendida como algo que tem existência em si, sem orientação, sem interior. Para Descartes, a produtividade natural é a própria produtividade de Deus. Ele entende que a Natureza é o próprio Deus (DESCARTES, 1994 [1641]).

Entretanto, prenuncia-se uma segunda mudança no pensamento de Descartes acerca da ideia de Natureza. Se num primeiro momento ela mantinha a concepção de Natureza original pensada a partir do mundo real. Depois, passa a considerar outra filosofia da Natureza, ressaltando a importância da investigação dos sentidos humanos na percepção da realidade. Assim, nessa ideia de Natureza também pode ser considerado a maneira com apreendemos as coisas, os espaços, unidades de medidas dos corpos, ou seja, uma Natureza imaginada (MERLEAU-PONTY, 2006 [1995]).

Para Merleau-Ponty (2006 [1995]), no mecanicismo cartesiano há um esforço em resistir à idealização do mundo partindo do princípio das explicações dadas a ele de máquina simples. Nesse movimento dialético, pode-se dizer que a nova interpretação de Descartes da ideia de Natureza não a considera mais como partes extra partes. Ele reivindica o Eu no espaço, onde se referia à Natureza exterior ao homem.

Essa ruptura com sua concepção anterior de Natureza é reflexo também de seu questionamento sobre a unidade do corpo e da alma, colocando em análise se podem ser consideradas como uma única coisa ou não e, nesse caso, em que grau apresenta certa união.

Merleau-Ponty (2006 [1995]) tece uma crítica aos mecanicistas dizendo que estes partem de meios artificiais, como convenções, para definir a Natureza, conceituando algo que, para ele, é um artificial natural. Lenoble (2002 [1968], p 21) acrescentaria que uma "consciência que concebe e apreende a Natureza segundo o seu próprio dinamismo deixa-se cair na armadilha de uma Natureza panfísica e deixa-se engolir por ela."

Natureza divina para o sábio antigo, Natureza criada, mas que canta a glória de Deus para o Salmista e para Dante, a Natureza máquina que na obra dos primeiros mecanicistas dá ainda testemunho da sabedoria do divino Relojoeiro, não via tardar a perder essa significação: [...] o homem tem tão profundamente o sentimento da sua dependência que procura sempre um senhor; se não encontra em Deus, fará paradoxalmente reviver o mito naturista das primeiras idades: a Natureza volta a ser a sua senhora e a sua lei, mas então Natureza sem alma, Natureza coisa, mecanismo para triturar os homens e as almas, a que chamamos de Determinismo, Axioma eterno ou Materialismo histórico (LENOBLE, 2002 [1968], p 192).

Diversas ideologias religiosas influenciaram na concepção de Natureza, por exemplo, o catolicismo e o protestantismo desenvolveram dois caminhos diferentes. Apesar do protestantismo gerar uma espécie de movimento antinatural nas estruturas ideológicas de sua religião ao deixar de lado a visão contempladora da Natureza e experimentar uma acepção religiosa em detrimento dela, seus crentes - em comparação aos católicos - adequavam-se melhor a uma ciência que iria predominar no estudo da Natureza, ou seja, uma tendência a uma ciência laica. Os protestantes veem uma Natureza mecânica sem alma, passando a ser ferramenta de exploração (LENOBLE, 2002 [1968]).

Nesse sentido, para os filósofos, pesquisadores, estudiosos e cientistas da época, "conhecer é fabricar" (LENOBLE 2002 [1968], p 260). "[...] todos a despeito de todas as divergências de escolas e das polêmicas muitas vezes inflamadas, se encontram de acordo ao afirmar que a Natureza é uma máquina e que a ciência é a técnica de exploração dessa máquina. [O] século XVIII será o século dos autômatos" (LENOBLE 2002 [1968], p 261). 


\subsection{A concepção humanista de Natureza}

Essa corrente de pensamento caracteriza-se pela reação violenta de afetividade e sentimento ao mecanicismo frio.

Do sentido antropológico do Ser e do sentido absoluto, o termo Natureza, desdobra-se em dois sentidos. Considerando que tudo é representação humana, já que partimos do princípio da experiência do Ser e da sua interpretação do mundo, a Natureza aparece como um "conjunto de todos os objetos dos sentidos". "A Natureza é o que um Ser sensível percebe. É um simples correlativo da percepção. Perde toda a sua selvageria" (MERLEAU-PONTY, 2006 [1995], p 34).

O segundo sentido considera a Natureza a partir de seu entendimento e construção de leis gerais para explicá-la. Assim há "um a priori da Natureza" (MERLEAU-PONTY, 2006 [1995], p 34).

Merleau-Ponty (2006 [1995]) compartilha com Whitehead (1930) a ideia de que esse duplo sentido dado à palavra Natureza é um equívoco, dito de outa forma, não seria adequado entender separadamente a Natureza como algo que nada podemos dizer senão pela apreensão de nossos sentidos, ou que ela é entendida e refletida em construções de leis gerais de seu funcionamento.

A filosofia de Kant é uma tentativa para unificação desses dois sentidos no que tange o entendimento da Natureza, ou seja, uma junção entre a receptividade e espontaneidade, entre o entendimento e a razão por meio do juízo (MERLEAU-PONTY, 2006 [1995]). O juízo determinante refere-se à tomada de posicionamento e a aceitação sobre essa opção determinada.

[...] Kant introduz uma finalidade a propósito do/e não no conceito de Natureza. A finalidade não pertence aos seres naturais, mas devemos pensá-la a propósito deles (MERLEAU-PONTY, 2006 [1995], p 36).

Para Kant, a finalidade não deve ser entendida como fator produtor dos fenômenos naturais. De qualquer maneira, a concepção de Natureza de Kant ainda é influenciada pelo mecanicismo de Galilei e Newton. Em contrapartida, Fredrich Schelling desenvolve sua filosofia da Natureza calcada, sobretudo, numa oposição ao mecanicismo de Galilei e Newton, desconsiderando essa dualidade entre causalidade e finalidade por meio de uma atividade que as transcenderia e que as harmonizaria, que se daria pela atividade criadora da arte (SCIACCA, 1962).

[...] Brunschvicg não se conforma com a ideia de Natureza como conjunto de relações necessárias que engendrariam a realidade, mas formula a idéia de Mundo como encontro de sincronismos e recorre por isso a um novo tipo de subjetividade e de objetividade que o idealismo ignora (MERLEAU-PONTY, 2006 [1995], p 53).

A idéia cartesiana de Natureza não tinha sido completamente exorcizada por Kant. Certamente, com Kant a Natureza já não é construída por Deus, mas pela Razão humana. Entretanto, o conteúdo permanece idêntico.

Não obstante, Kant fora o primeiro a levantar-se contra a idéia de naturante [...] (MERLEAU-PONTY, 2006 [1995], p 57).

Mas o que se busca nessa corrente de pensamento, sobretudo por meio da filosofia de Schelling, é promover uma tentativa de reconciliação sujeito-objeto, ou seja, entre o indivíduo e a Natureza, mesmo que talvez nem ele, nem seus seguidores tenham conseguido atingir uma explicação que satisfizesse tal tentativa (MERLEAU-PONTY, 2006 [1995]).

Schelling em seus estudos e reflexões questiona a ideia de naturante-naturado que se tem da Natureza, ou seja, da dicotomia apresentada anteriormente em que existiria uma Natureza produtora, criadora, e o naturado que seria o resultado dessa produção, uma Natureza produto. Schelling argumenta que o "[...] naturado não é um efeito morto, e a Natureza não é um produto [...]” (MERLEAU-PONTY, 2006 [1995], p 59). Ele está interessado em reexaminar a ideia de que existe um ser pré-reflexivo, ou seja, de uma primeira Natureza (erste Natur). "O que Schelling quer dizer é que se redescobre a Natureza em nossa percepção antes da reflexão" (MERLEAU-PONTY, 2006 [1995], p 63). Mas salienta que a nossa percepção não está isenta à 
reflexão. Whitehead (1930) corrobora tal assertiva e acrescenta que o pensamento é algo que está além da Natureza, por exemplo, em sua crítica à teoria absoluta de tempo e espaço, e diz que o pensamento não ocupa espaço, ou volume de espaço.

Assim, Schelling combate a visão de Natureza coisa, de uma visão de que é possível conceituá-la, como em Hegel. Para Hegel nada há de espiritual na Natureza. Ele traça a concepção de espírito absoluto no sentido de uma verdade universal, não finita. Nesse sentido ele opõe o espírito finito (que recebe a verdade do espírito absoluto) à Natureza que se situa no espírito absoluto de um modo ideal. O espírito absoluto seria a união de si próprio com a Natureza, mas essa dada numa idealidade. Assim, no plano real ela é vista como um objeto, coisa dada, e por meio de conceitos (na idealidade para reter sua verdade) procura constituí-la sob um enfoque processual em três estádios: Natureza mecânica; Natureza física e; Natureza orgânica (HEGEL, 1985 [1807]; SCIACCA, 1962).

Leibniz também afirma que não há espírito na Natureza, mas sim um começo de sentido que cabe ao homem dar forma, conteúdo e sentido a ele. Entretanto, conforme afirma Merleau-Ponty (2006 [1995]), por meio desses pensamentos de Schelling e Leibniz, não se deve incorrer no erro de afirmar que a Natureza só existe por nós, porque nós a concebemos, ou que a Natureza só existe fora de nós. Não é isso que Schelling busca elucidar. "A Natureza caminha, por uma série de desiquilíbrios, para a realização do homem que se torna seu termo dialético. [...]" (MERLEAU-PONTY, 2006 [1995], p 70).

Shelling apresenta o aparecimento do homem com uma espécie de recriação do mundo, como o advento de uma abertura. A Natureza, por essa abertura, quando chega a criar o homem, vê-se ultrapassada em algo novo. Mas o inverso é igualmente verdadeiro. Não só a Natureza deve tornar-se visão, mas é preciso que o homem se torne Natureza [...] (MERLEAU-PONTY, 2006 [1995], p 77).

Num contexto de humanização da Natureza, os filósofos e cientistas passam a enfocar uma posição de Natureza que existe por si própria, mas que nos é revelada pelo senso de consciência, ou seja, pelo mundo percebido que leva ao conhecimento do homem.

Para Henri Bergson (1999 [1939]), a matéria não pode ser explicada pelo realismo e nem pelo idealismo, ou seja, não se deve reduzir a matéria à representação que temos dela e nem a entender como algo que produz no sujeito representações dela. "A matéria [...] é um conjunto de imagens. E por imagens entendemos uma certa existência que é mais do que aquilo que o idealista chama uma representação, porém menos do que aquilo que o realista chama uma coisa [...]" (BERGSON, 1999 [1939], p 2).

[Bergson afirma que só] [...] se pode elaborar um conceito válido de Natureza se for encontrado algo na junção do Ser e do nada. [...]. [Mas, para isso] [...] [a] fim de elaborar esse conceito, é preciso sair do positivismo ou do negativismo que sempre mantêm um distanciamento entre o objetivo e o subjetivo e impossibilitam, portanto, esse subjetivo-objetivo que sempre será a Natureza (MERLEAU-PONTY, 2006 [1995], p 115).

Bergson tece uma crítica de grande expressão aos métodos mecanicista e positivista presentes nas correntes de pensamentos filosóficas e científicas, sobretudo na França. "Conhecer por intuição, significa viver dentro de uma coisa e por isso o intuicionismo é um modo absoluto de conhecimento, diverso do modo relativo de análise" (SCIACCA, 1962, p 202).

Em Husserl a ideia de Natureza relaciona-se à totalidade, ao mundo, ou seja, ela envolve tudo. Ela seria a esfera das coisas puras (HUSSERL, 2006 [1913]). Assim, ele retoma a preocupação de Schelling em reabilitar a ideia de Natureza no âmbito da filosofia reflexiva, não se orientando ao estudo das coisas dadas, mas sim dos fenômenos. Nesse sentido, por meio da redução fenomenológica seria possível atingir os objetos puros.

Quando nos tornamos sujeitos teóricos no movimento de análise de algo ou algum fenômeno no mundo, objetificando algo para análise, há certo distanciamento do Eu em relação à coisa a ser analisada. Essa postura espontânea adotada pelo observador tenta assumir uma posição de indiferença, "e o correlato dessa indiferença seria a coisa pura" (MERLEAU-PONTY, 2006 [1995], p. 119). 
Essa concepção da Natureza [de entender a percepção da coisa pura] não é, por certo, a única possível; há uma outra concepção igualmente natural, [...].

Esse universo, ao considerá-lo em si mesmo, remete a um universo primordial. $\mathrm{O}$ universo da teoria subentende um universo já presente. Atrás desse mundo existe um mundo mais originário, anterior a toda atividade, "mundo antes de toda tese": é o mundo percebido. Enquanto o primeiro se apresenta como um mundo construído, ele oferece-se em carne e osso, Leibhaft. Possui um caráter insuperável, abaixo do qual nada existe. Ao contrário, o universo das coisas puras é um universo minado, atrás do qual há a solidez do percebido: a referência de um ao outro está inscrita no próprio sentido do blosse Sache [simples coisa ou pura coisa]. Quando examinamos a significação de uma coisa, encontramos a história dessa significação sedimentada nela: a extensão cartesiana tem uma história nela; as blosse Sachen aparecem como idealizações, são conjuntos ulteriores construídos sobre a solidez do percebido. Se permanecermos na blosse Sache, não compreendemos nada como, por exemplo, o movimento absolutamente relativo em Descartes; para que isso tenha um sentido, é preciso ter uma experiência absoluta do movimento, saber o que é o movimento, poder falar dele: isso é retornar a um nível prévio que desempenhará o papel de uma fonte (MERLEAU-PONTY, 2006 [1995], p. 120 e 121).

Para Merleau-Ponty "cumpre admitir, portanto, que este mundo não é aparência em relação àquele das puras coisas, mas, ao contrário, que é fundador em relação a essas puras coisas" (MERLEAU-PONTY, 2006 [1995], p 128). Posto isso, independente dos esforços das diversas correntes de pensamento, Merleau-Ponty (2006 [1995]) afirma que não tem como a Natureza aparecer diante de nós. Nesse contexto, alguns filósofos passam a centrar seus esforços na questão da produção natural ao abordar a discussão sobre a Natureza.

Isso quer dizer que a produção natural não deve ser pensada a partir do nada, como se existisse um ponto inicial, onde há ausência, e que a partir disso fosse concebida a produção natural. "A Natureza nunca é estabelecida assim, mas como um englobante, como um tipo de ser no qual já nos descobrimos investidos antes de toda a reflexão" (MERLEAU-PONTY, 2006 [1995], p 135).

Segundo Bachelard (1978 [1934]), com frequência o que se chama de natural é resultado de má teoria. Nesse sentido Merleau-Ponty (2006 [1995], p 136) tece o seguinte questionamento:

Mas se, como ele [Bachelard], se tem consciência da artificialidade do pensamento, não se necessita encontrar para esta um contrário dialético, esse oponente sendo, senão a Natureza, pelo menos o percebido?

\subsection{O Natural Percebido: Tentativa de Retorno do Natural à Ideia de Natureza}

Merleau-Ponty (2006 [1995]) afirma que se a Natureza é um englobante, ela deve ser pensada a partir de algo não determinado, ou seja, não se valendo de conceitos pré-concebidos. Nesse sentido, primeiramente deve-se pensá-la através da experiência, de maneira sistematizada ou regulada.

O aparelho, em física quântica, já não tem o mesmo sentido que em física clássica. Para os clássicos, o aparelho é o prolongamento dos nossos sentidos. [...] Os aparelhos em mecânica ondulatória deixam de ser amplificadores; [...] O aparelho não nos apresenta o objeto. Realiza uma antecipação do nosso fenômeno, assim como uma fixação. [...] A Natureza conhecida é uma natureza artificial (MERLEAU-PONTY, 2006 [1995], p 150).

Merleau-Ponty (2006 [1995]) chama atenção que deve ser considerada não a decisão do que é ou não realidade, mas a imagem pela qual será entendida, pois tanto na ciência clássica quanto na moderna a apreensão de um objeto se dá pela experiência, mas ela própria "é uma violação da Natureza" (MERLEAUPONTY, 2006 [1995]p 157). Assim, a realidade seria também uma noção a afirmar.

Na ciência moderna, "renuncia-se [...] às idéias de uma Natureza como complexo de fatos sem significação que se bastaria a si mesmo e teriam relações passivas ou acidentais". Neste sentido, a Natureza 
não é "o conjunto dos objetos dos sentidos ou a soma dos objetos dos sentidos, como afirmara Kant" (MERLEAU-PONTY, 2006 [1995], p 186).

Para Whitehead (1930) há uma espécie de reciprocidade entre o ser senciente e a Natureza. O ser senciente é parte da Natureza, funcionando como qualquer evento da Natureza. Aquilo que percebo é, ao mesmo tempo, para mim e nas coisas. "A percepção se faz a partir do interior da Natureza [...]. Natureza [segundo Whitehead] é, portanto, aquilo que permanece intato após o desvelamento perceptivo, o que é indiferente aos olhares que pouso nela" (MERLEAU-PONTY, 2006 [1995], p 192 e 193).

Assim, Whitehead concebe a Natureza como sendo um evento de passagem e postula a teoria da passagem da Natureza. Para tanto, ele considera a percepção como elemento fundamental na tentativa de compreensão da Natureza. O termo evento é elemento chave na construção de seu raciocínio. Com efeito, evento é o que só aparece uma vez, o único. Deve-se salientar que sua concepção não se limita à constatação de transcendência da Natureza, caso contrário seria incoerente em sua proposição buscar devolver à Natureza o seu caráter real e não ideal.

Nesse sentido, a Natureza é mais essencialmente, para ele, ocorrência. Isso significa que ela está inteiramente em cada uma de suas aparições, e nunca é exaurida por nenhuma delas. Ela está total em cada instante, imanência e transcendência são fortemente unidas por Whitehead (1930) no seu entendimento de Natureza. Não existe um meio de deter a Natureza a fim de olhá-la, se tentarmos melhorar o nosso acesso a ela, o nosso esforço é em vão. A Natureza é sempre nova a cada percepção, mas nunca é passado. A Natureza é algo que se continua que nunca é apreendido em seu começo, ainda que se revele (aparentemente) sempre nova (WHITEHEAD, 1930).

Whitehead não quer mais definir a matéria e a Natureza pelo presente e pelo instante. Ele nega que o passado não seja mais e que o futuro ainda não seja. A Natureza para ele é concebida como um desdobramento espaço-temporal (WHITEHEAD, 1930; MERLEAU-PONTY, 2006 [1995]). Há um tempo da Natureza em si, mas um tempo da Natureza enquanto participamos dela, e não há meios então de falar de Natureza em si a partir da Natureza viva. Para ele a noção de Natureza é uma noção-limite, por isso aplica o termo passagem da Natureza, ou que a Natureza é um processo.

Pode-se afirmar que Merleau-Ponty (2006 [1995]) corrobora com as asserções de Whitehead (1930) até então apresentadas. Nesse sentido, Merleau-Ponty expressa sua noção de Natureza dizendo que:

[...] [o] conceito de natureza não evoca somente o resíduo daquilo que não foi construído por mim, mas uma produtividade que não é nossa, embora possamos utilizá-la, ou seja, uma produtividade originária que continua sob as criações artificiais do homem. É simultaneamente o que há de mais velho e é algo sempre novo (MERLEAU-PONTY, 2006 [1995], p 204).

Whitehead (1930) propõe uma nova concepção de matéria, concepção orgânica de matéria, doravante resultando em uma nova noção de Natureza (SCIACCA, 1962).

Para Whitehead (1930) Natureza é o que observamos na percepção através dos sentidos. Ele acrescenta que nesse senso de percepção nós estamos conscientes de algo que não é um pensamento, mas que já é autossuficiente para um pensamento ou para a sua formação. $O$ senso de percepção tem em sua essência um elemento que não é pensamento, que seria o senso de consciência.

Ele salienta que pensar sobre a Natureza é diferente do senso de percepção da Natureza. Assim, alguma coisa percebida é percebida como uma entidade, que é o final - terminus - do senso de consciência, algo que para o pensamento está além do fato do senso de consciência.

Whitehead busca dar elementos para sustentar a importante distinção que faz em sua obra acerca da ideia de que a matéria não deve ser considerada como substrato da Natureza. Ele estende e aprofunda essa tese por meio de explanação acerca das relações espaciais e temporais questionando a teoria do espaço e tempo absolutos.

By this I do not mean that any doubt should be thrown on facts of space and time as ingredients in nature. What I do mean is the 'the unconscious presupposition of space and time as being that within which nature is set.' This is exactly the sort of presupposition which tinges thought in any reaction against the subtlety of philosophical criticism. My theory of the formation of the scientific 
doctrine of matter is that first philosophy illegitimately transformed the bare entity, which is simply an abstraction necessary for the method of thought, into the metaphysical substratum of these factors in nature which in various sense are assigned to entities as their attributes; and that, as second step, scientists (including philosophers who were scientists) in conscious or unconscious ignoration of philosophy presupposed this substratum, qua substratum for attributes, as nevertheless is in time and space (WHITEHEAD, 1930, p 20 e 21).

Nesse sentido, espaço e tempo é que deveriam ser atributos da substância e não o contrário. Mas, como eles não são palpáveis, a matéria foi colocada como solucionadora de tal impasse, ou seja, para Whitehead (1930) essa ação é incoerente. "What we find in space are the red of the rose and the smell of the jasmine and the noise of cannon. We have all told our dentists where our toothache is. Thus space is not a relation between substances, but between attributes" (WHITEHEAD, 1930, p 21).

Na teoria absoluta, o tempo é a sucessão ordenada de instantes sem duração. O que acontece no tempo ocupa o tempo. Essa relação dos eventos ao tempo ocupado, ou seja, essa relação de ocupação, é uma relação fundamental da Natureza ao tempo. Assim, essa teoria requer que estejamos conscientes de duas relações fundamentais, a do ordenamento do tempo entre os instantes do tempo e os estados da Natureza em que acontecem tais instantes (WHITEHEAD, 1930).

Como critica a lógica da teoria absoluta do espaço e tempo, Whitehead (1930) apresenta uma série de perguntas, entre elas, talvez duas representem a base fundamental de seu questionamento, são elas: Por que em tal teoria a causa que influencia a mente à percepção teria qualquer característica em comum com a Natureza aparente? O que se sabe sobre a mente humana que nos autorizaria inferir qualquer característica particular da causa que tivesse influencia na mente acerca de efeitos particulares?

Whitehead (1930) estende tal crítica dizendo que em função da transcendência do tempo além da Natureza, pode-se presumir que a causa (Natureza causal) ocupe o tempo (referindo-se ao processo de pensamento ocupar tempo), mas a mente não ocupa volumes de espaço. Nesse sentido, a Natureza causal parece não ter razão em por que deveria ocupar espaço. Logo, o espaço pareceria algo meramente aparente no mesmo sentido que a Natureza aparente é meramente aparente. Essa teoria da Natureza não apresenta as características necessárias que envolvam nosso conhecimento perceptivo. Portanto, suas críticas são sintetizadas da seguinte maneira:

(i) a teoria do espaço e tempo absolutos busca a causa de um dado conhecimento ao invés de procurar sua característica;

(ii) essa teoria assume um conhecimento do tempo nele mesmo separado dos eventos relacionados no tempo, ou seja, parte do princípio que o tempo é uma entidade independente;

(iii) tal teoria assume um conhecimento de espaço nele mesmo também separado dos eventos relacionados no espaço.

Resumidamente, para Whitehead (1930) a matéria não é o substrato do espaço e do tempo, e o que é percebido na Natureza é a relação entre os atributos da substância. Para ele, espaço e tempo é que deveriam ser atributos da substância, justificando assim uma teoria relacional da espacialidade e a temporalidade dos atributos das substâncias. Assim, o espaço não deve ser entendido como uma entidade absoluta.

Portanto, a teoria proposta por Whitehead (1930) recusa as concepções mecanicistas e também o vitalismo, como em Bergson acerca do élan vital. A unidade da Natureza em Whitehead se refere a toda Natureza como concrescência.

Whitehead (1930) conclui então que existem três componentes da Natureza: fatos; fatores, e; entidades. Ele define fato como o término indiferenciado do senso de consciência; fatores são os términos do senso de consciência, diferenciados como elementos do fato e; entidades são fatores em sua função como términos do pensamento. Nesse contexto, tais entidades são entidades naturais. O pensamento é maior que a Natureza, portanto existem entidades para o pensamento que não são entidades naturais.

A estrutura do complexo natural não pode nunca ser completa no pensamento, assim como os fatores do fato não podem nunca ser exauridos no senso de consciência. Whitehead (1930) afirma que a não exaustividade é um caráter essencial sobre o nosso conhecimento de Natureza. O autor ainda acrescenta que também a Natureza não exaure a matéria do pensamento. 
Nenhuma característica da Natureza que seja imediatamente colocada ao conhecimento pelo senso de consciência pode ser explicada. Isto é impenetrável pelo pensamento, no sentido de que seu caráter essencial peculiar que entra na experiência pelo senso de consciência é para o pensamento meramente o guardião de sua individualidade como um objeto puro (WHITEHEAD, 1930).

Thus for thought 'red' is merely a definite entity, though for awareness 'red' has the content of its individuality. The transition the 'red' of awareness to the 'red' of thought is accompanied by a definite loss of content, namely by the transition from the factor 'red' to the entity 'red'. This loss in the transition to the thought is compensated by the fact that thought is communicable whereas senseawareness is incommunicable (WHITEHEAD, 1930, p 13).

Fica muito claro o caminho que Whitehead nos apresenta para tratar o tema Natureza, ou seja, o pensamento está presente na maneira como lidamos com ela, e é justamente nesse ponto que ele chama atenção, para que tenhamos consciência de que a propriedade de algo que descrevemos ou estudamos contém entidades naturais e não naturais.

Portanto, o que é percebido é a relação entre os atributos da substância, onde a matéria não é a substância fundamental da Natureza. Não é a matéria (na Natureza) o que percebemos em nossos sentidos.

Os reflexos da corrente científica de que percebemos a matéria na Natureza fizeram com que na ciência e na filosofia os estudos não mais considerassem somente o que a mente conhece sobre a Natureza, mas também o que a Natureza faz com a mente, ou seja, são levadas também em consideração as relações entre a revelação da Natureza no senso de consciência com a mente do indivíduo. "The result has been disastrous both to science and to philosophy, but chiefly to philosophy. It has transformed the grand question of the relations between nature and mind into the petty form of interaction between the human body and mind" (WHITEHEAD, 1930, p 27).

Whitehead (1930) critica a noção de Natureza bifurcada em coisa e mente. Nessa concepção, a Natureza, que é o fato apreendido na consciência, contém nele o verde das árvores, a música dos pássaros, o calor do sol, a dureza das cadeiras e a sensação de maciez do veludo. Já a Natureza que se enquadraria como a causa da apreensão do fato na consciência seria o sistema de moléculas e elétrons (pautados em hipóteses teóricas) que afetam a mente ao produzir a consciência de uma Natureza aparente. Portanto, o ponto de convergência dessas duas Naturezas é a mente, a Natureza causal sendo influente e a Natureza aparente sendo efluente.

Para os pensadores que defendem a Natureza como um sistema unitário, o tempo e o espaço apareceriam para fornecer todas as relações necessárias em tal sistema. Todavia, para Whitehead (1930) a Natureza não pode ser concebida a partir das teorias absolutas do espaço e tempo, onde cada um é um sistema independente, critica já apresentada nos parágrafos anteriores.

O dado fundamental na ciência é comumente considerado: o tempo; o espaço; as qualidades do material e; as relações entre os objetos materiais. Todavia, como já apontado anteriormente, o dado na forma como ocorrem nas leis científicas não tem relação com todas as entidades que se apresentam em nossa percepção da Natureza.

De fato, não há mundo objetivo correspondente ao mundo de nossas experiências vividas. A Natureza se encarrega de fazer as abstrações para nós, decidindo que tipo de vibrações nós iremos ver e ouvir, quais tipos de coisas iremos notar e lembrar. Portanto, na teoria de Whitehead (1930), o estudo da Natureza deve ser abarcado pela discussão detalhada do entendimento dos tipos de entidades e tipos de relação entre tais entidades que são reveladas a nós em nossa percepção da Natureza.

\section{Algumas Considerações Finais}

De maneira geral afirma-se que a concepção sistêmica de Natureza tem um papel importante no ambiente acadêmico brasileiro. As concepções sistêmicas de Natureza, por exemplo, apresentada na Teoria Geral dos Sistemas por Bertalanffy (2016 [1968]), assim como a concepção de modelos de balanços energéticos proposta por Odum (1996), ou a visão de Agroecossistema dada em Gliessmann (2005), têm suas raízes numa concepção mecanicista da Natureza.

A teoria da Natureza como um evento de passagem pode ser entendida como uma relação dos objetos situados nos eventos revelados pelo nosso senso de consciência. A Natureza não é um agregado de entidades 
independentes, cada uma passível de ser isolada. A Natureza isolada em diferentes aspectos é uma abstração científica eleita como método em diversos campos disciplinares na busca de entender um fenômeno na Natureza.

Na Natureza entendida como evento de passagem se pode discernir relações mútuas definidas entre eventos componentes de tal estrutura, em que suas relativas posições podem ser expressas parcialmente em termos de espaço e parcialmente em termos de tempo. Cada evento tem sua própria característica peculiar. Assim, a Natureza é uma estrutura de eventos e cada evento tem sua posição nessa estrutura e sua própria característica peculiar de qualidade. As relações estruturais mútuas entre eventos são ao mesmo tempo espaciais e temporais. "Thus when you think of space alone, or of time alone, you are dealing in abstractions, namely, you are leaving out as essential element in the life of nature as known to you in the experience of your senses" (WHITEHEAD, 1930, p 168).

Assim, considerando uma Natureza não desnaturada, pode-se afirmar que ela é tudo, são os objetos, somos nós em nossas diversas ações no mundo vivido. O mundo vivido substancialmente depende da maneira como o percebemos, concepção que é central - sob a forma de evento percipiente - na teoria da Natureza como um evento de passagem.

Acredita-se que a maneira como um indivíduo ou um grupo social entende a Natureza tem relação direta com suas atitudes no mundo vivido, atitudes estas construídas culturalmente.

\section{Notas}

Este artigo é desdobramento de um dos capítulos da tese "Os agricultores de Buri (SP) percebidos no seu olhar sobre a vegetação nativa" defendida pelo autor - sob orientação do Prof. Dr. Adilson Avansi de Abreu no programa de Pós-Graduação em Geografia Física, departamento de Geografia da Faculdade de Filosofia, Letras e Ciências Humanas da Universidade de São Paulo.

\section{Referências}

BACHELARD, C. Filosofia do novo espírito científico. Trad. Joaquim José Moura Ramos. São Paulo: Abril Cultural (coleção Os pensadores), 1978 (original 134), p 3 - 179.

BERGSON, H. Matéria e memória: Ensaio sobre a relação do corpo com o espírito. Trad. Paulo Neves da Silva. São Paulo: Martins Fontes, 1990 (original 1939). p 2- 58

BERTAlanfyy, L. von. Teoria Geral do Sistemas: fundamentos, desenvolvimentos e aplicações. Petrópolis, Rj: Vozes, $1^{\text {a }}$ reimpressão 2016. [1968], 360 p.

DESCARTES. Meditações. Trad. J. Guinsburg e Bento Prado Júnior. $3^{\text {a }}$ ed. São Paulo: Abril Cultural (coleção Os pensadores), 1985 (original 1641), p 92 - 138.

EAGLETON, T. A ideia de cultura. Trad. Sandra Castello Branco. São Paulo: Fundação Editora Unesp, 2003, p $9-50$.

EHRARD, J. L'idée de nature en France dans la première moitié di XVIII ${ }^{\mathbf{e}}$ siècle. Paris: Bibliothèque de L'Evolution de l'Humanité, 1994 (original 1963). P. 11-22.

GLIESSMANN, S. R. Agroecologia: processos ecológicos em agricultura sustentável. trad. Maria José Guazelli. $3^{\mathrm{a}}$ ed. Porto Alegre: UFRS, 2005, 653 p.

HEGEL, G. W. F. A Fenomelogia do Espírito. Trad. Henrique Cláudio de Lima Vaz. $3^{\text {a }}$ ed. São Paulo: Abril Cultural (coleção Os pensadores), 1985 (original 1807), p 1 - 75.

HUSSERL, E. Ideias para uma fenomenologia pura e para uma filosofia fenomenológica: Introdução geral à fenomenologia pura. Trad. Márcio Suzuki. São Paulo: Ideias e Letras, 2006, p. 59-72; 201-208.

LENOBLE, R. História da ideia de natureza. Trad. Teresa Louro Pérez. Lisboa: Edições 70, 2002. 367 p.

MERLEAU-PONTY, M. A natureza. São Paulo: Martins Fontes, 2000. 448p.

ODUM, H. T. Environmental Accounting: Emergy and Environmental Decison Making. New York: John Wilwy \& Sons, 1996, 370 p.

SCIACCA, M. F. História da Filosofia. Do século XIX aos nossos dias. São Paulo: Editora Mestre Jou, 1962, p. 1-60.

WHITEHEAD, A. N. The concept of nature. Cambridge: Cambridge University Press, 1930. 